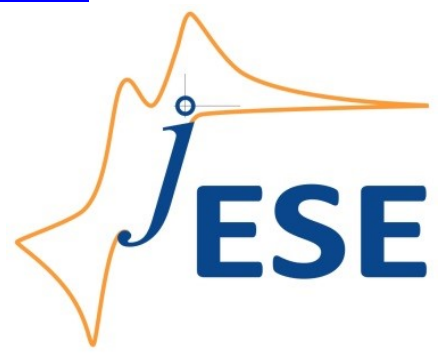

Open Access : : ISSN 1847-9286

www.jESE-online.org

Original scientific paper

\title{
The template-assisted electrodeposition of platinum nanowires for catalytic applications
}

\author{
Soha Mohajeri ${ }^{\bowtie}$, Abolghassem Dolati ${ }^{凶}$, Sahar Hashemi Daryan \\ Department of Materials Science and Engineering, Sharif University of Technology, Tehran, Iran \\ Corresponding authors -E-mail: ${ }^{\bowtie}$ smohajeri@alum.sharif.edu, ${ }^{\circledR}$ dolati@sharif.edu \\ Received: January 6, 2018; Revised: February 13, 2018; Accepted: February 14, 2018
}

\begin{abstract}
Template-assisted electrodeposition technique was applied to synthesize platinum nanowires (Pt NWs) on polycarbonate templates (PCT) with pore diameters of 15, 50, and $100 \mathrm{~nm}$ for catalytic applications. Influences of sulfuric acid added to the electrolyte, different potential scanning rates and different pore diameters of templates on the electrodeposition process of Pt NWs were investigated by electrochemical techniques, including voltammetry and chronoamperometry methods. It was confirmed that at lower scan rates and in acidic solutions, electrodeposition of platinum on templates with larger pores is controlled by diffusion. The potential range for deposition of Pt NWs was determined and the potentiostatic technique was utilized by applying various potentials of different durations to fabricate the NWs. The morphological characteristics of Pt NWs were examined using the scanning electron microscopy (SEM). It was shown that the growth of Pt NWs on PCT $50 \mathrm{~nm}$ followed a pine-tree pattern, while the Pt NWs grew spherically on PCT $100 \mathrm{~nm}$. The uniform and compact shape of Pt NWs was verified by the transmission electron microscopy (TEM). The catalytic activities of the prepared Pt NWs with the same exchanged charge density for hydrogen adsorption/desorption and methanol oxidation reactions were determined by the cyclic voltammetry (CV) testing, and the superior electrocatalytic performance was detected for Pt NWs prepared on PCT $50 \mathrm{~nm}$. This enhanced catalytic activity was attributed to the higher surface-to-volume ratio, larger electrochemical active surface area and higher density of exposed active sites accessible on the pine-tree morphology of these Pt NWs compared to the spherical structure of Pt NWs fabricated on PCT $100 \mathrm{~nm}$. This makes Pt NWs prepared on PCT 50 $\mathrm{nm}$ to be a promising catalyst for direct methanol fuel cells (DMFCs).
\end{abstract}

\section{Keywords}

Platinum nanowires; Polycarbonate templates; Electrodeposition; Hydrogen adsorption/desorption; Methanol oxidation reaction 


\section{Introduction}

In recent years, noble-metal nanostructures have attracted extensive research attention due to their promising potentials for numerous electrocatalytic applications including a variety of fuel cell systems, electrochemical biosensors and batteries [1]. In particular, the synthesis of platinumbased nanostructures such as nanotubes, nanoparticles and nanowires with specific structural features has been an area of considerable interest [2]. This happened owing to the enhanced catalytic capabilities of platinum for applications in direct methanol fuel cells (DMFCs) which are considered as highly promising power sources for electric vehicles and portable electronic devices [3]. Limited supply and high cost of this precious metal, however, have impeded its commercial utilization. Moreover, the formation of intermediate species in the process of methanol oxidation tends to poison the Pt surface and diminish the oxidation rate, reducing thus the catalytic performance of this metal [4]. In order to improve the catalytic activity and the poisoning tolerance of Pt catalysts, various researchers have focused their investigations on the replacement of zero-dimensional (OD) Pt nanoparticles with one-dimensional (1D) Pt nanowires (Pt NWs) $[5,6]$. Several structural features offered by Pt NWs such as anisotropic morphology and high surface-tovolume ratio can enhance their mass-transport and electron-transfer kinetics, leading to the superior catalytic activity of Pt for hydrogen evolution and methanol oxidation reactions [7].

Although various techniques such as electron-beam deposition [8], solvothermal synthesis [9], physical vapor deposition [10], electron beam lithography [11] and plasma sputtering [12] have been applied to fabricate Pt NWs, electrodeposition [13] has been proven as the most commonly used deposition method due to its low cost and high productivity [14]. In particular, the templatebased electrodeposition of Pt NWs has been established as an effective method due to its simplicity and high-yielding process. This method provides a well-organized approach for the fabrication of isolated nanowire arrays with uniform diameters determined by the pore diameter of the template [15]. It is generally accepted that the diameter of nanowires plays a fundamental role in their functionality. As the diameter of nanowires decreases, their surface-to-volume ratio increases and consequently, the variation of the surface energy significantly influences the surface state and the related physical and chemical properties [16]. Although many studies have investigated the template-based electrodeposition of Pt NWs, very few researchers have examined distinct morphological and structural properties of Pt NWs fabricated on templates with different pore diameters. Also, a limited research has so far been reported on the electrocatalytic activity of Pt NWs for hydrogen adsorption/desorption and methanol oxidation reactions.

The current study aims to examine the electrodeposition of Pt NWs on polycarbonate templates (PCT) with different pore diameters and determine the dependence of their electrochemical behavior and morphological properties upon the pore size of templates. The work has been focused on the hydrogen adsorption/desorption on Pt NWs and the influence of their diameter on the methanol oxidation reaction performances.

\section{Experimental}

The electrochemical deposition of Pt NWs was carried out in a typical three-electrode cell and the potential was recorded with reference to a saturated calomel electrode (SCE). A pure platinum plate with the surface area of $2 \times 1 \mathrm{~cm}^{2}$ was used as the counter electrode and polycarbonate templates (PCT) with the surface area of $0.2 \times 1 \mathrm{~cm}^{2}$, pore diameter of 15,50 , and $100 \mathrm{~nm}$, pore length of $6 \mu$, and pore density of $10^{8}$ pores $/ \mathrm{cm}^{2}$ were employed as the working electrode. In order to impart conductivity to the working electrode, the solution sides of the templates were coated 
with $50 \mathrm{~nm}$-thick Au layer via sputtering. Two electroplating baths were prepared and all the reagents were of analytical grade from Merck. In the first bath, $0.05 \mathrm{M} \mathrm{H}_{2} \mathrm{PtCl}_{6}$ was added dropwise to deionized water-hydrochloric acid mixture $(\mathrm{pH}$ 1.6) under continuous stirring. In order to study the influence of sulfuric acid adding on the electrodeposition of Pt NWs, the second electroplating bath was prepared. $0.1 \mathrm{M} \mathrm{H}_{2} \mathrm{SO}_{4}$ was added to $0.05 \mathrm{M} \mathrm{H}_{2} \mathrm{PtCl}_{6}$ solution with vigorous mixing during addition, and the final solution was added drop-wise to a mixture of deionized water and hydrochloric acid with already adjusted $\mathrm{pH}$ of 1.6. Both electroplating baths were purged with $\mathrm{N}_{2}$ at room temperature for $2 \mathrm{~h}$. To optimize the deposition potentials suited for the deposition of Pt NWs, linear sweep voltammograms and chronoamperometry curves were recorded by an EG\&G Princeton Applied Research (PAR) potentiostat and influences of $0.1 \mathrm{M} \mathrm{H} \mathrm{H}_{2} \mathrm{SO}_{4}$ added to the electrolyte, different potential scanning rates, and different pore diameters of templates on the electrodeposition process of Pt NWs were investigated. Afterwards, the potential range for deposition of Pt NWs was determined and subsequently, the potentiostatic method was utilized by applying various potentials of different durations to synthesize the nanowires. The surface and cross-sectional morphologies of the obtained Pt NWs were examined by a scanning electron microscope (SEM, TESCAN Model), after dissolving the polycarbonate membranes by dichloromethane. A transmission electron microscopy (TEM, EM-10C Model) analysis was used to evaluate the Pt NWs nanostructure. The electrocatalytic activity of Pt NWs obtained with the same exchanged charge density was assessed in a cell containing the PC templates filled with the Pt NWs (working electrode, $0.2 \times 1 \mathrm{~cm}^{2}$ ) and a platinum sheet (counter-electrode, $2 \times 1 \mathrm{~cm}^{2}$ ). The supplied bias and current were controlled by an Autolab PGSTAT 302 electrochemical system. The cyclic voltammetry (CV) tests for hydrogen adsorption/desorption reactions were conducted in an argon-purged $0.5 \mathrm{M} \mathrm{H}_{2} \mathrm{SO}_{4}$ solution at room temperature under continuous stirring and the obtained CV curves were used to estimate the electrochemically active surface area (ECSA) of Pt NWs catalysts. The methanol oxidation reaction activity of Pt NWs was studied by CV tests in a $0.5 \mathrm{M} \mathrm{H}_{2} \mathrm{SO}_{4}$ electrolyte containing $2 \mathrm{M} \mathrm{CH} 3 \mathrm{OH}$, and the optimum diameter of $\mathrm{NWs}$ for obtaining the maximal catalytic efficiency was determined.

\section{Results and discussion}

\section{Electrochemical studies of the Pt NWs deposition}

The influence of sulfuric acid added to the plating bath on the electrodeposition of Pt NWs was studied. Figure 1 demonstrates the cathodic voltammetry curves of PCT $50 \mathrm{~nm}$ working electrode, measured in a pure bath and $\mathrm{H}_{2} \mathrm{SO}_{4}$-containing solution in the potential range of 0 to $-2000 \mathrm{mV}$ vs. SCE at the scan rate of $5 \mathrm{mV} / \mathrm{s}$. It can be observed that in the presence of the sulfuric acid, higher current densities were measured and the curve shifts to more positive potentials. The higher value of slope indicates that the electrodeposition of $\mathrm{Pt}$ ions occurs at a higher rate in a $\mathrm{H}_{2} \mathrm{SO}_{4}{ }^{-}$ containing bath compared to the pure deposition bath, depicting that the sulfuric acid plays a catalytic role in the deposition of Pt NWs.

In order to investigate the effect of various potential scan rates on the electrodeposition of Pt NWs, the linear voltammetry curves recorded in a $\mathrm{H}_{2} \mathrm{SO}_{4}$-containing solution in the range of 0 to $-1000 \mathrm{mV}$ vs. SCE at the scan rates of 20,50 and $100 \mathrm{mV} / \mathrm{s}$ are illustrated in Figure 2. Two irreversible peaks can be detected in the cathodic branches of the curves obtained at the scan rates of 20 and $50 \mathrm{mV} / \mathrm{s}$. The peaks are ascribed to the successive reduction of $\mathrm{Pt}^{4+}$ to $\mathrm{Pt}^{2+}$ ions and of $\mathrm{Pt}^{2+}$ ions to $\mathrm{Pt}$, respectively, according to the following reactions: 


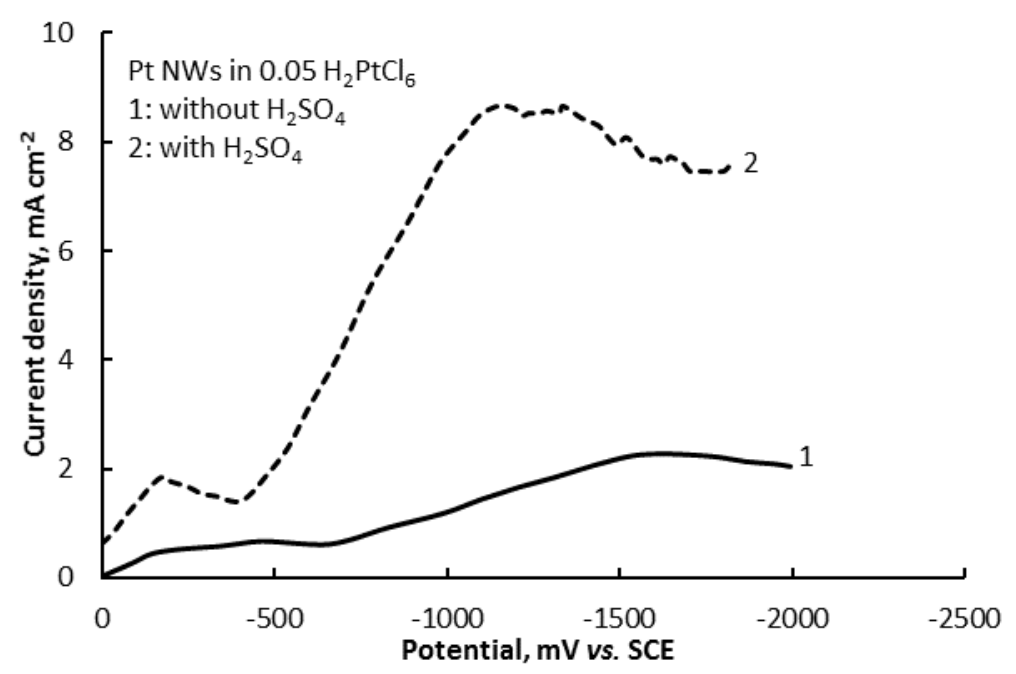

Figure 1. Effect of $0.1 \mathrm{M} \mathrm{H}_{2} \mathrm{SO}_{4}$ added to the plating bath on electrodeposition of Pt NWs on PCT $50 \mathrm{~nm}$ at the scan rate of $5 \mathrm{mV} \mathrm{s}^{-1}$

$\left[\mathrm{PtCl}_{6}\right]^{2-}+2 \mathrm{e}^{-} \rightarrow\left[\mathrm{PtCl}_{4}\right]^{2-}+2 \mathrm{Cl}^{-}$

$\left[\mathrm{PtCl}_{4}\right]^{2-}+2 \mathrm{e}^{-} \rightarrow \mathrm{Pt}+4 \mathrm{Cl}^{-}$

A typical feature of the diffusion-controlled electrodeposition is that an increase of the scan rate shifts the reduction peaks to more negative potentials and causes higher current densities along with a simultaneous increase in the deposition rates. This behavior can be attributed to the fact that at higher scan rates, the cations have a lower opportunity for deposition on the surface and therefore need a higher energy and overpotential for deposition. Figure 2, depicts such a feature, suggesting that the electrodeposition of $\mathrm{Pt}$ is under the mass transfer control. With the increase of the scan rate from 20 to $50 \mathrm{mV} / \mathrm{s}$, the mass transfer is enhanced, leading to the intensified adsorption of platinum ions on the working electrode. Consequently, the potential difference between the cathodic peaks increases. Finally, at the scanning rate of $100 \mathrm{mV} / \mathrm{s}, \mathrm{a}$ single wide peak is observed due to the lack of the deposition duration that leads to the decrease of the deposited platinum species on the cathode.

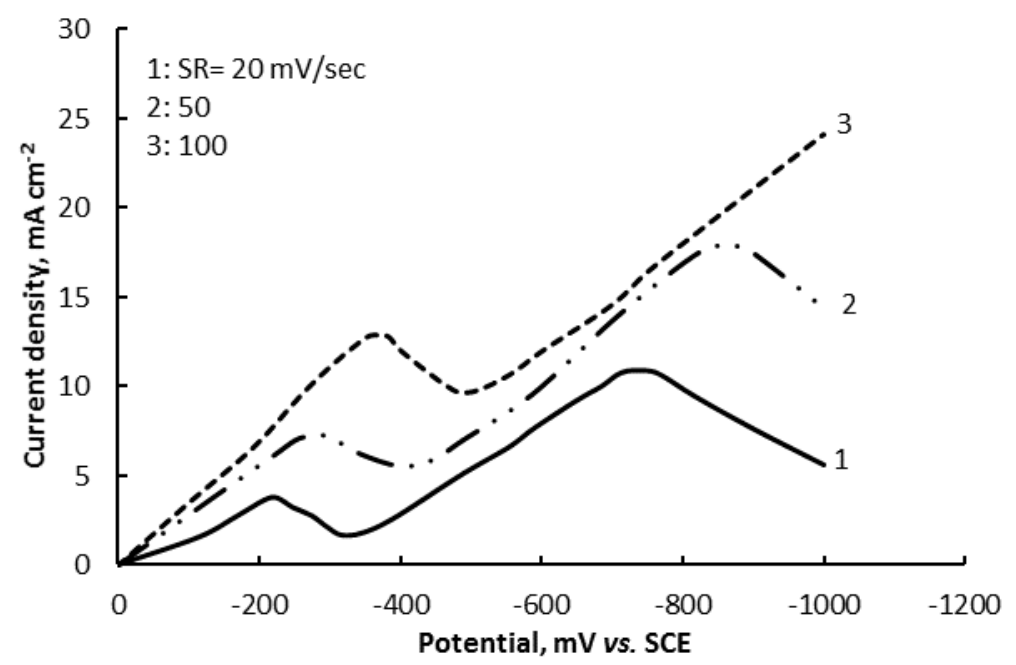

Figure 2. Linear sweep voltammograms of Pt NWs deposited on PCT $50 \mathrm{~nm}$ at different scan rates.

The influence of the template pore diameter $(15,50$, and $100 \mathrm{~nm})$ on the linear voltammetric curves in the range of 0 to $-1000 \mathrm{mV} v \mathrm{~s}$. SCE at a scan rate of $50 \mathrm{mV} / \mathrm{s}$ is depicted in Figure 3 . No diffusion peaks were observed for deposition on PCT $15 \mathrm{~nm}$ and therefore, it can be concluded that the charge transfer governs the system kinetics. This can be attributed to the higher surface- 
to-volume ratio of the small pores with the diameter of $15 \mathrm{~nm}$, which provides facile pathways for mass transfer and more effective exposure of active surface sites for the progressive ions flux to the cathode surface. Thus, the diffusion of the solution species is fast and the deposition current is restricted by the electron transfer at the working electrode. This is a characteristic of deposition reactions in which the charge transfer is rate determining $[17,18]$. However, for PCT 50 and $100 \mathrm{~nm}$, diffusion controls the curves. The increase of pore diameters leads to the increase of the deposition current density and shifts the curves to more negative potentials. This can be due to the larger size of the pores and transference of more platinum ions into the pores, which requires higher overpotentials for reduction.

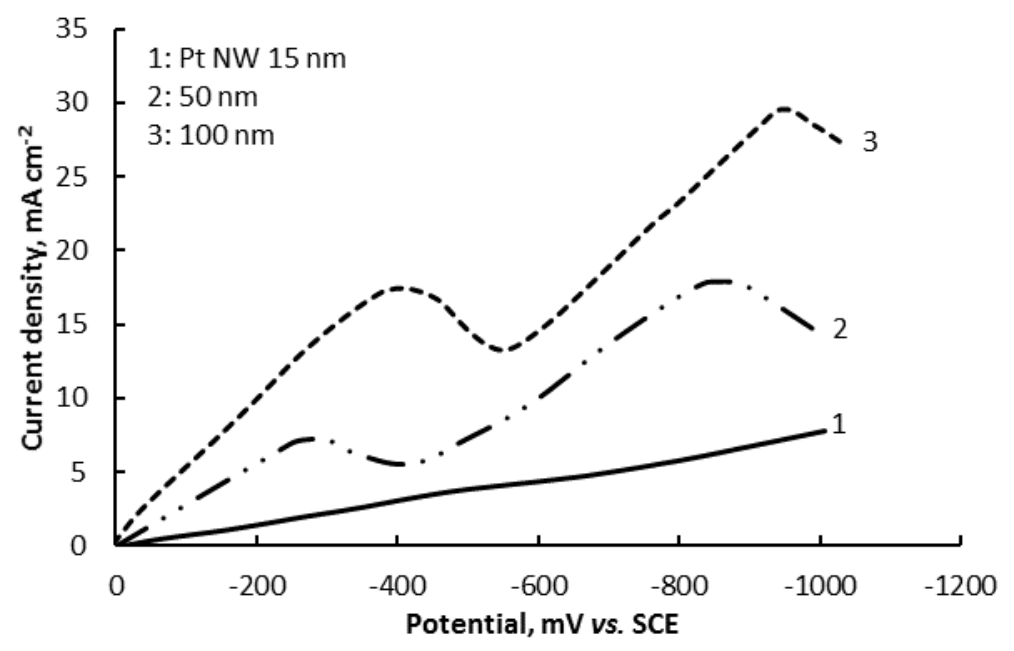

Figure 3. Linear sweep voltammograms for electrodeposition of Pt NWs on templates with different pore diameters at scan rate of $50 \mathrm{mV} \mathrm{s}^{-1}$

Figure 4 illustrates the potentiostatic $i-t$ transients of Pt NWs deposited on PCT 50 and $100 \mathrm{~nm}$ at $-400 \mathrm{mV}$ vs. SCE. Based on the characteristic shape of the chronoamperometry curves, a nucleation and growth mechanism can describe the electrodeposition process having the rate of growth limited by diffusion [19]. At the initial times, the current density increases due to the nucleation process and 3D growth of the nuclei. Subsequently, diffusion controls the current drops and the deposition. Finally, the current density remains relatively constant and filling up the pores occurs. These curves also reveal that the deposition trend does not change as the pores diameters increase from 50 to $100 \mathrm{~nm}$.

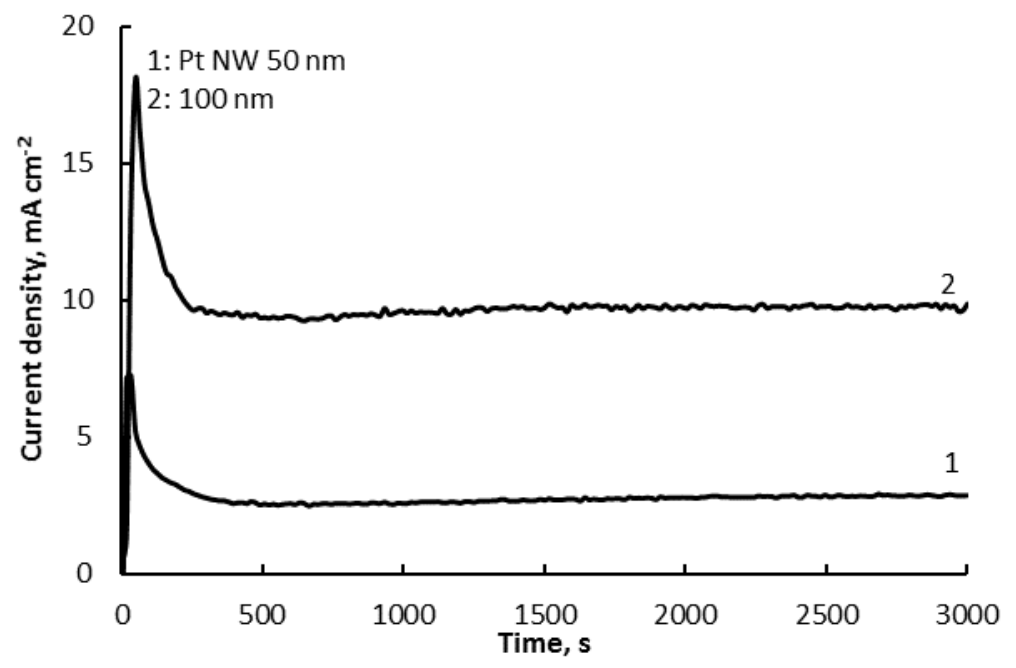

Figure 4. Chronoamperometry curves for deposition of Pt NWs on PCT 50 and $100 \mathrm{~nm}$ at $-400 \mathrm{mV}$ vs. SCE. 


\section{Morphological study of Pt nanowires}

From the linear sweep voltammetry curves shown in Figure 3, the reduction potential region for the deposition of Pt NWs on templates with pore diameters of 50 and $100 \mathrm{~nm}$ can be determined. Due to the locations of peaks in the diffusion-controlled electrodeposition of nanowires, the values of -250 and $-400 \mathrm{mV}$ were determined as the starting potentials for the deposition of $\mathrm{Pt}$ NWs on PCT 50 and $100 \mathrm{~nm}$, respectively. The potentiostatic method was utilized to synthesize the nanowires by applying various potentials in the range of -250 to $-400 \mathrm{mV}$ for different durations.

Morphologies of Pt NWs deposited on the PCT $50 \mathrm{~nm}$ from a $\mathrm{H}_{2} \mathrm{SO}_{4}$-containing solution at different potentials in the range of -250 to $-400 \mathrm{mV}$ for $500 \mathrm{~s}$ were analyzed by SEM. In order to study the surface morphology of prepared Pt NWs, the deposited samples were cut, and the surface areas of the templates were locally dissolved in $\mathrm{CH}_{2} \mathrm{Cl}_{2}$. Figures 5 (a)-(c) illustrate the cross-sectional SEM images of Pt nanowires grown on PCT $50 \mathrm{~nm}$ at $-250,-350$ and $-400 \mathrm{mV}$, respectively. Figures 5 (d)-(f) show the SEM images at a higher magnification, and it can be observed that the average lengths of the nanowires vary between 1 to $4.5 \mu$. According to Figures 5 (a) and (d), it can be observed that at $-250 \mathrm{mV}$, the growth of nanowires is uniform but due to the lack of deposition time, they do not meet the surface of the template. In Figures 5 (b) and (e), it seems that at increased applied potential to $-350 \mathrm{mV}$, the holes are not completely filled due to the short deposition time, but the growth of nanowires occurs simultaneously and uniformly. Figures 5 (c) and ( $f$ ) demonstrate that at more negative potential of $-400 \mathrm{mV}$, due to the hydrogen evolution reaction, the efficiency of the nanowires deposition declines, leading to a less uniform growth of nanowires.

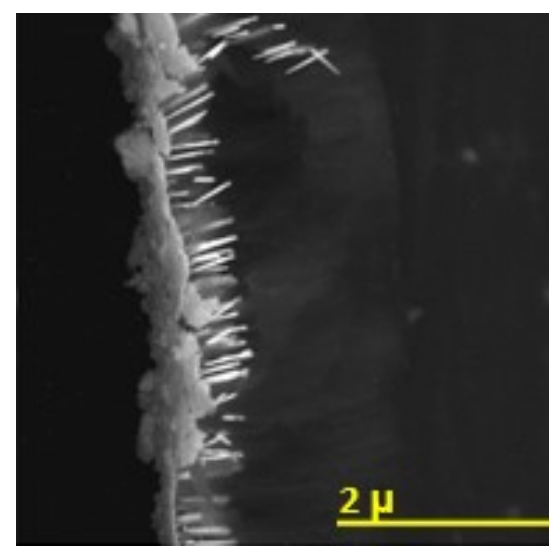

(a)

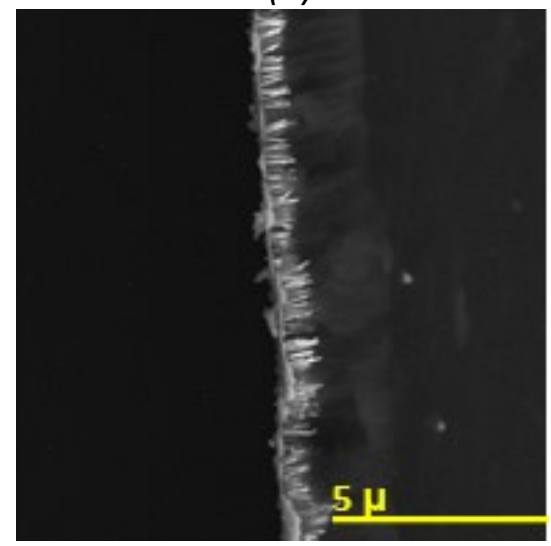

(d)

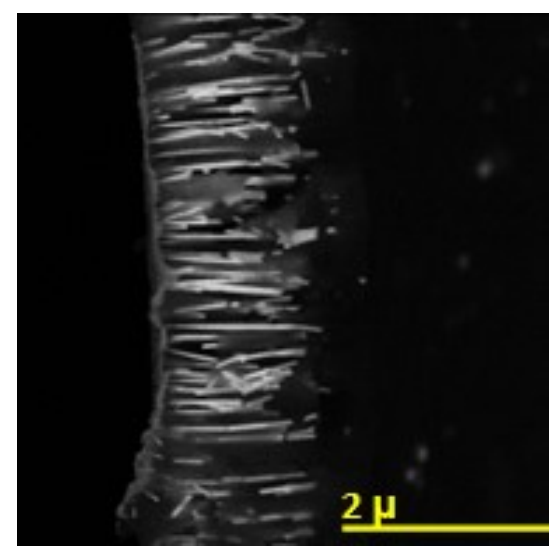

(b)

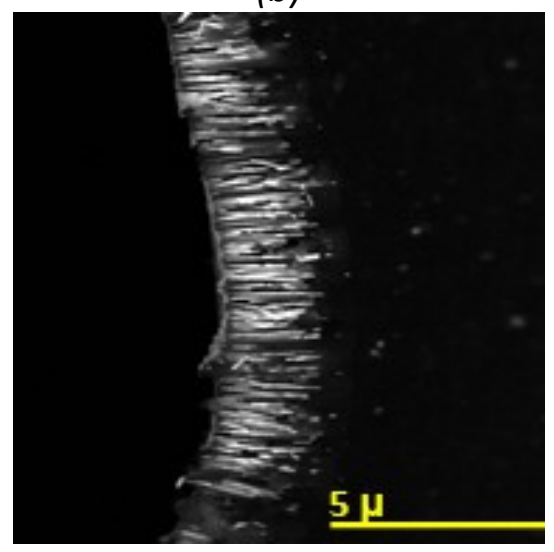

(e)

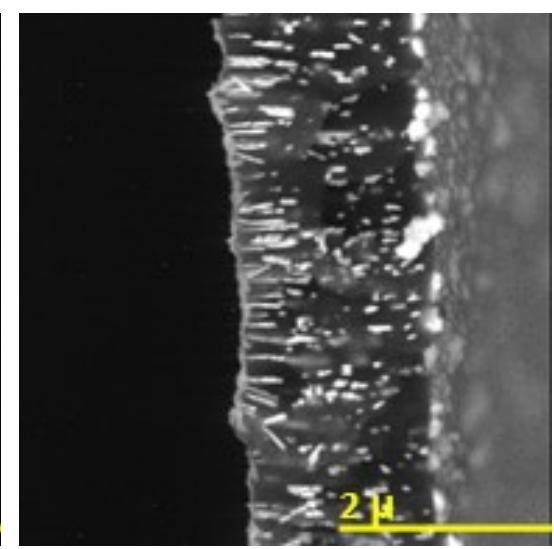

(c)

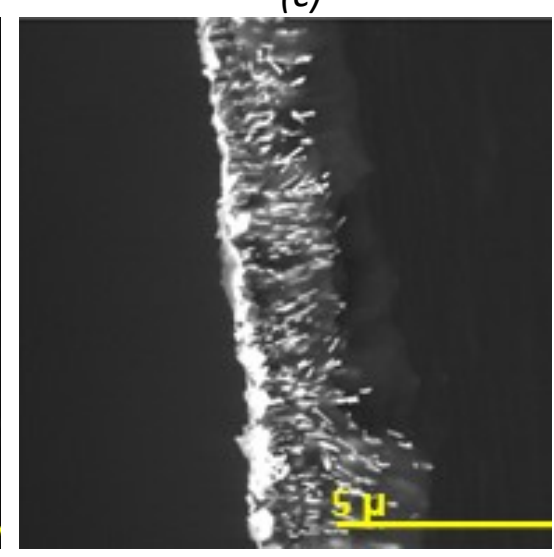

(f)

Figure 5. SEM images of PT NWs electrodeposited for $500 \mathrm{~s}$ on PCT $50 \mathrm{~nm}$ at the potential of:

(a), (d) $-250,(b),(e)-350$, and (c), (f) $-400 \mathrm{mV}$. 
In order to examine the consequences of increasing the deposition duration on the surface and cross-sectional morphology of Pt NWs deposited on PCT 50 and $100 \mathrm{~nm}$, the potentials of -350 and $-400 \mathrm{mV}$ were applied for $3000 \mathrm{~s}$. According to Figures 6 (a) and (b), Pt NWs deposited on PCT $50 \mathrm{~nm}$ at $-350 \mathrm{mV}$, represent the tree branches and resemble pine needles.

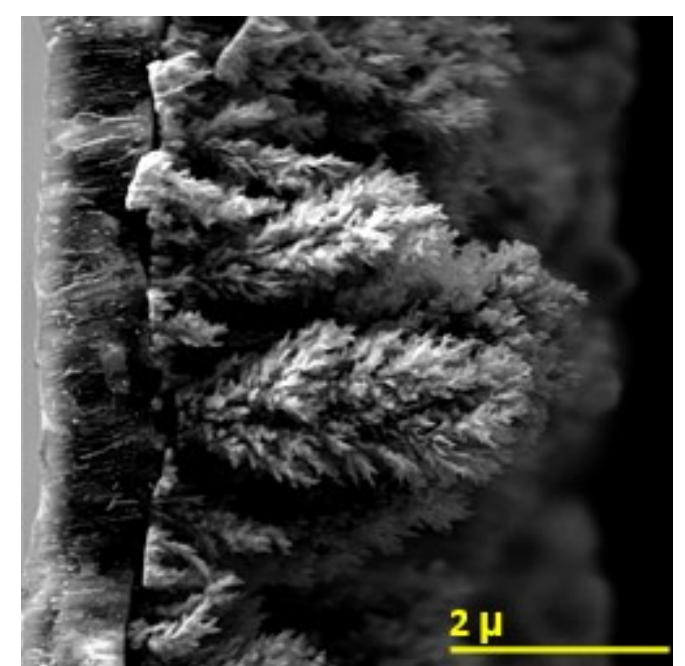

(a)

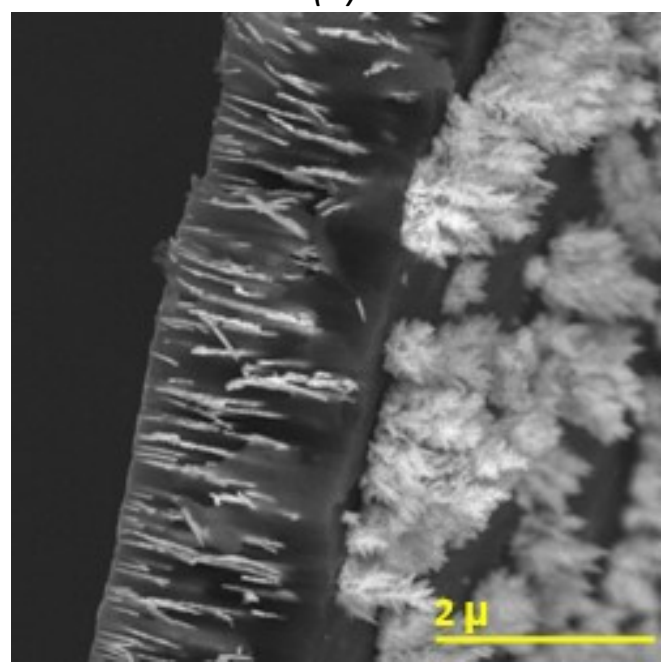

(c)

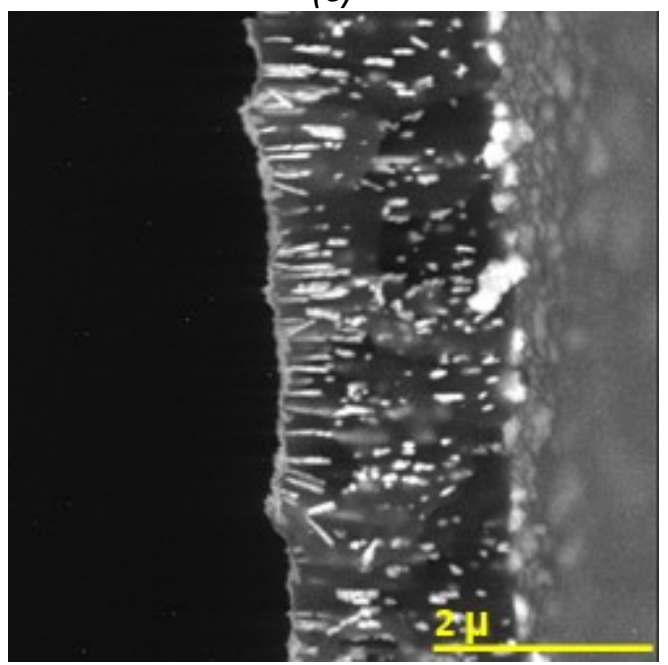

(e)

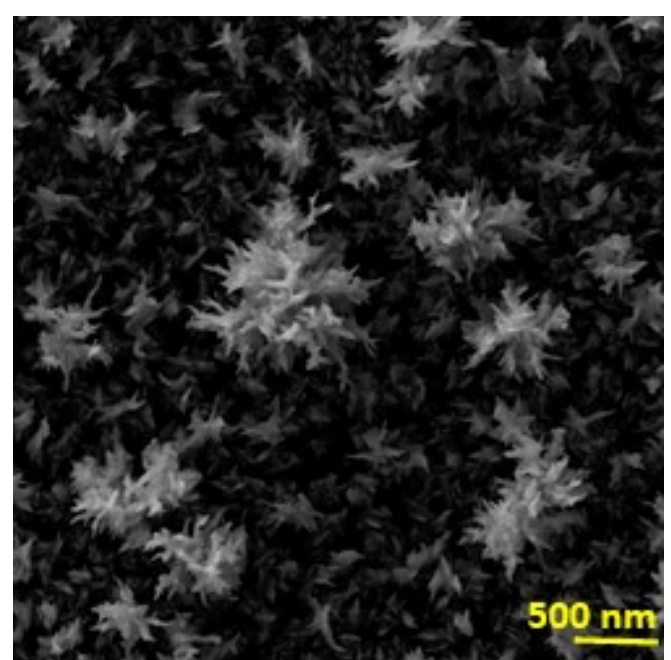

(b)

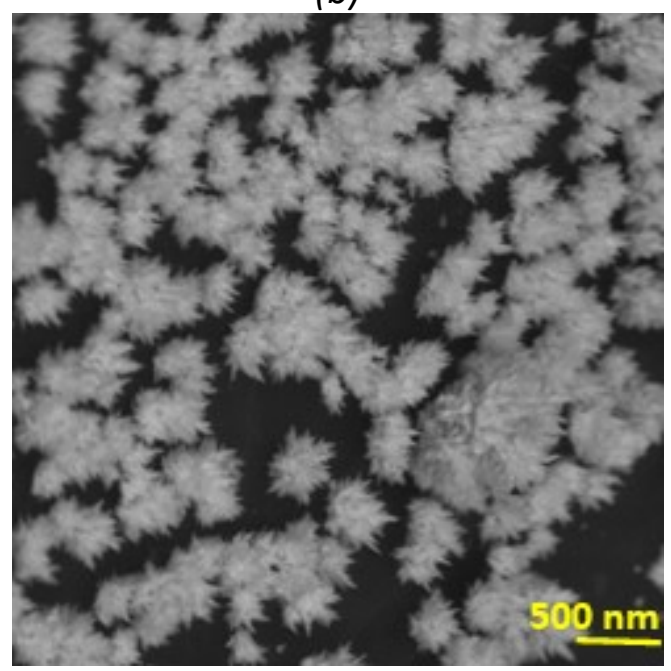

(d)

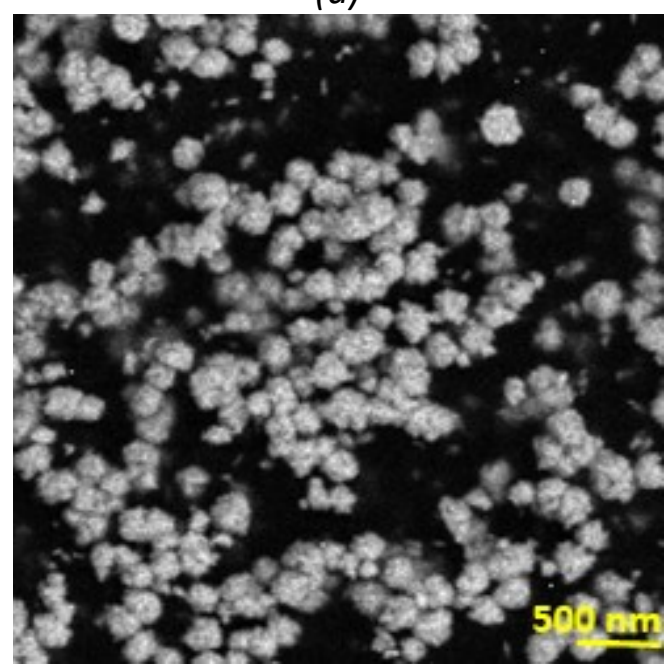

(f)

Figure 6. Surface and cross-sectional morphology of Pt NWs electrodeposited for 3000 s on PCT $50 \mathrm{~nm}$ at the potential of (a), (b) $-350,(c),(d)-400 \mathrm{mV}$, and on PCT $100 \mathrm{~nm}$ at the potential of (e), (f) $-400 \mathrm{mV}$. 
This pine-tree morphology can be attributed to the tendency of the multifaceted platinum nuclei to branch, spread, and dramatically overgrow on the surface. It is noteworthy to mention that unlike the nanowires of other fcc metals such as gold, copper, nickel, and cobalt, the Pt NWs do not follow a cauliflower growth pattern and do not tend to form caps on the surface of the templates. Alternatively, they continue their overgrowth rather than overlapping, and manifest pine-tree structures that are single crystalline, and their facets grow close to the $\{001\}$ plane [20]. As depicted in Figures 6 (c) and (d), at the potential of $-400 \mathrm{mV}$, the Pt NWs on the PCT $50 \mathrm{~nm}$ do not grow uniformly along the pores, reaching the surface of the template and continuing their growth on the surface. As mentioned before, the evolution of hydrogen at more negative potentials accounts for the non-uniform growth of platinum nanowires. Figures 6 (e) and (f) demonstrate the spherical growth of Pt NWs on the PCT $100 \mathrm{~nm}$.

It was confirmed that the nucleation process of Pt NWs on both PCT 50 and $100 \mathrm{~nm}$ follow the instantaneous mechanism in which the rate of new nuclei formation at the initial stage of deposition is high enough to immediately activate all the nucleation sites. However, the number of nuclei remains constant during the growth process and the 3D growth of the nuclei is limited by diffusion [21]. With regards to Figures 6 (d) and (f), at the same deposition potential of $-400 \mathrm{mV}$, the ratio of surface-to-volume of Pt NWs prepared on PCT $50 \mathrm{~nm}$ is larger than those deposited on PCT $100 \mathrm{~nm}$, and the driving force inside the smaller pores is higher, leading to the increase of nucleation density inside the pores with the size of $50 \mathrm{~nm}$. On the other hand, the mass transport inside smaller pores with the size of $50 \mathrm{~nm}$ is more limited by diffusion in comparison to the pores with the size of $100 \mathrm{~nm}$. Thus, the diffusion coefficient is smaller in PCT $50 \mathrm{~nm}$ and the 3D growth of the nuclei follows a pine-tree pattern. As the 3D growth inside the pores of PCT $100 \mathrm{~nm}$ is less restricted by diffusion and due to the lower concentration gradient inside larger pores, the nuclei are promoted to grow spherically on the PCT $100 \mathrm{~nm}$.

The influence of the pore size of templates on the length of nanowires deposited under the potential of $-400 \mathrm{mV}$ during $2000 \mathrm{~s}$ is represented in Figure 7. Due to the dissolution of polycarbonate membranes by dichloromethane, the nanowires are randomly distributed on the surface.

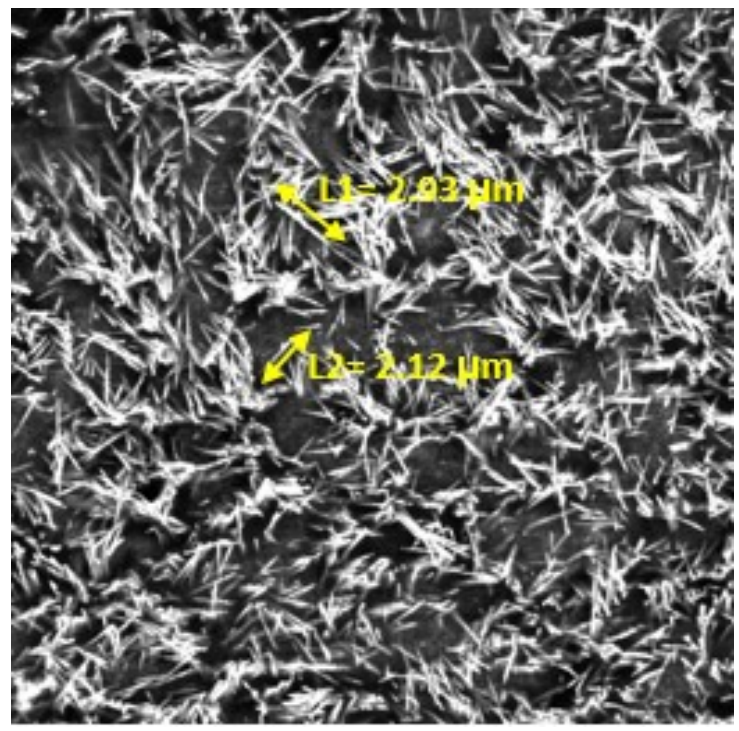

(a)

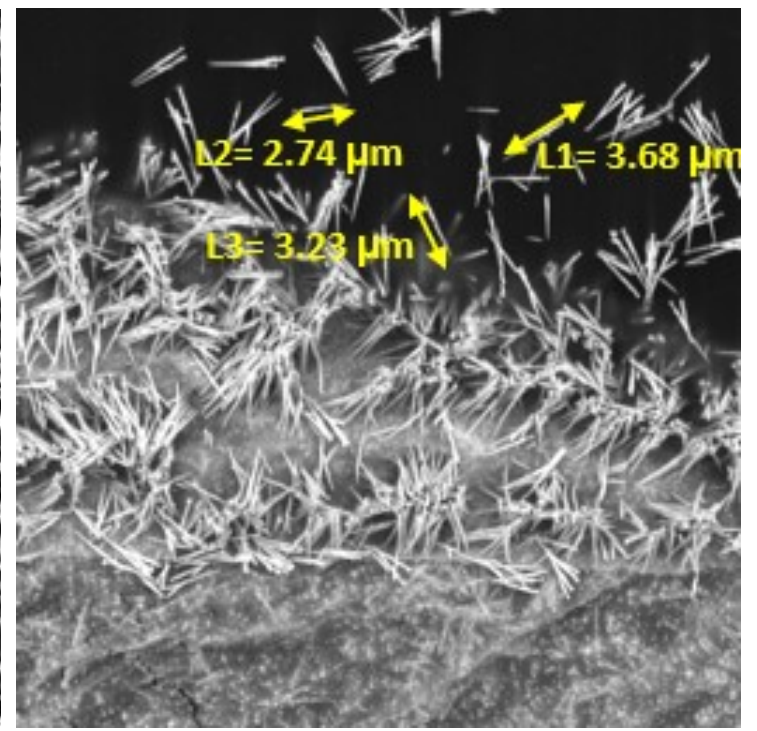

(b)

Figure 7. Surface morphology of Pt NWs electrodeposited at the potential of $-400 \mathrm{mV}$ for 2000 s on PCT: (a) 50 and (b) $100 \mathrm{~nm}$. 
The relatively short duration of applying the deposition potential resulted in the incomplete filling of the pores, and the average length of nanowires on PCT 50 (Fig. 7(a)) and $100 \mathrm{~nm}$ (Fig. 7(b)) are 2.5 and $3.3 \mu$, respectively. Since the system is controlled by diffusion at $-400 \mathrm{mV}$, the efficient surface area and the diffusion coefficient are higher in bigger pores [13], leading to the formation of longer nanowires.

\section{TEM characterization of Pt nanowires}

TEM images of Pt NWs deposited on the PCT $50 \mathrm{~nm}$ at $-400 \mathrm{mV}$ for $1000 \mathrm{~s}$ are depicted in Figure 8. According to Figure 8 (a), under the magnification of 1500, the nanowires are uniform, and their diameter is $100 \mathrm{~nm}$. Due to the short deposition duration, the lengths of these nanowires are in the range of 1.5-2.5 $\mu$, and they do not reach the thickness of template $(6 \mu)$. Figure 8 (b) depicts a uniform and compact nanowire having a diameter between 100 to $120 \mathrm{~nm}$ at different points. Since the end part of this nanowire is smaller and the deposition time is shorter than the required time for filling the pores, it can be concluded that this section belongs to the growing part of the nanowire. The dispersed grains inside the nanowire pertain to the growing nuclei and confirm that the nucleation and growth mechanism of nanowires are instantaneous and three dimensional, respectively.

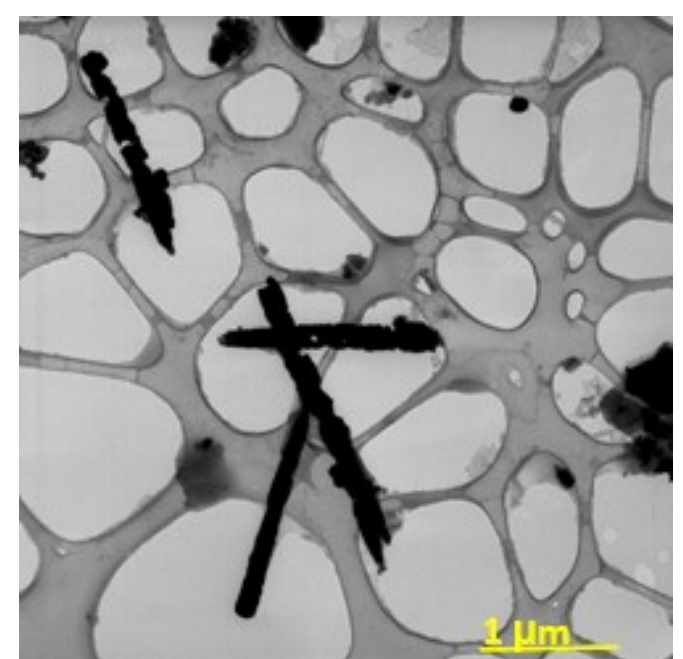

(a)

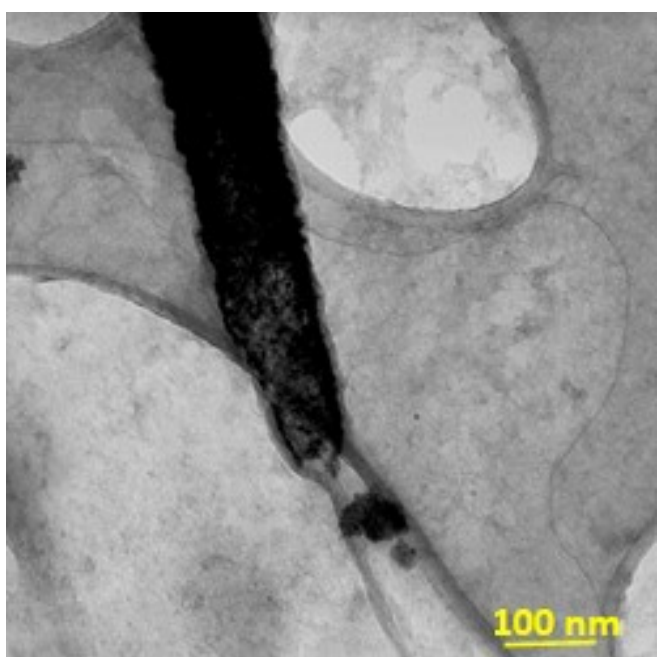

(b)

Figure 8. TEM images of Pt NWs electrodeposited for $1000 \mathrm{~s}$ at the potential of $-400 \mathrm{mV}$ on PCT $50 \mathrm{~nm}$ under the magnification of: (a) 1500 and (b) 8800

\section{Electrocatalysis in acidic solutions}

In order to investigate the catalytic activity of Pt NWs 50 and $100 \mathrm{~nm}$, the deposits obtained with the same exchanged charge density were compared. Based on Figure 4, the integration of chronoamperometric reduction current recorded over $3000 \mathrm{~s}$ for the Pt NWs $50 \mathrm{~nm}$ yielded the same amount of the exchanged charge as for the Pt NWs $100 \mathrm{~nm}$ recorded over $860 \mathrm{~s}$. Therefore, Pt NWs prepared at the potential of $-400 \mathrm{mV}$ for $3000 \mathrm{~s}$ on PCT $50 \mathrm{~nm}$ and for $850 \mathrm{~s}$ on PCT $100 \mathrm{~nm}$ were selected for studying the influence of nanowires diameter on their electrocatalytic activity.

\section{Adsorption/desorption of hydrogen}

The cyclic voltammograms shown in Figure 9 compare the hydrogen adsorption/desorption performance of Pt NWs deposited at the potential of $-400 \mathrm{mV}$ for $3000 \mathrm{~s}$ on PCT $50 \mathrm{~nm}$ and for $850 \mathrm{~s}$ on PCT $100 \mathrm{~nm}$, in a $0.5 \mathrm{M} \mathrm{H}_{2} \mathrm{SO}_{4}$ solution at a scan rate of $50 \mathrm{mV} / \mathrm{s}$. Both catalysts display 
peaks associated with the strong and weak adsorption/desorption of hydrogen molecules in anodic and cathodic sweeps in the sulfuric acid solution [22]. The existence of multiple peaks in both the cathodic and anodic scans, instead of one broad peak, reveals that various crystallographic planes of platinum participated in the reactions [23]. The upward and downward peaks are ascribed to hydrogen desorption $\left(\mathrm{P}^{\mathrm{d}}\right.$ and $\left.\mathrm{P}_{2}\right)$ and $\left(\mathrm{P}_{1}^{\mathrm{a}}\right.$ and $\left.\mathrm{P}_{2}{ }_{2}\right)$ adsorption, respectively. Since the hydrogen desorption peaks for Pt NWs $50 \mathrm{~nm}$ are approximately 10 to $30 \mathrm{mV}$ more negative than that of Pt NWs $100 \mathrm{~nm}$, it can be concluded that the hydrogen binding energy is lower on the nanowires prepared on PCT $50 \mathrm{~nm}$. The inferior hydrogen binding energy expedites the hydrogen desorption from the surface of nanowires and consequently, enhances the catalytic performance of nanowires. Moreover, the potentials of hydrogen adsorption peaks on Pt NWs 50 $\mathrm{nm}$ are more negative, and their current values are higher compared with those of Pt NWs 100 $\mathrm{nm}$. This implies that a great quantity of hydroxide species is produced on the electrode. Furthermore, the integration area of hydrogen desorption peaks for Pt NWs $50 \mathrm{~nm}$ surpasses the Pt NWs $100 \mathrm{~nm}$, indicating the higher amount of active surface area and thus, the more enhanced catalytic performance of the nanowires prepared on PCT $50 \mathrm{~nm}$.

The electrochemical active surface area (ECSA) of Pt NWs was estimated from the area of desorption of atomic hydrogen on the CV curves in Figure 9, between 0 and $-300 \mathrm{mV}$, via the following equation [24]:

$$
\mathrm{ESCA}=\frac{Q_{H}}{m c}
$$

In eq. (3), $Q_{H}$ is the total charge $\left(\mathrm{mC} \mathrm{cm}{ }^{-2}\right), m$ is actual Pt loading $\left(\mathrm{mg} \mathrm{cm}^{-2}\right)$ on the substrate, and $c$ signifies the charge required to oxidize a monolayer of hydrogen on a $\mathrm{Pt}$ surface $\left(0.21 \mathrm{mC} \mathrm{cm}^{-2}\right)$. The ECSA values of Pt NWs 50 and $100 \mathrm{~nm}$ are calculated to be 51.32 and $44.56 \mathrm{~m}^{2} \mathrm{~g}^{-1}$, respectively, indicating that Pt NWs $50 \mathrm{~nm}$ are capable of exposing sufficient active sites to guest molecules, leading to their superior electrocatalytic activity. This behavior can be due to the larger surface-to-volume ratio of Pt NWs $50 \mathrm{~nm}$, as well as their unique pine-tree morphology (Fig. 6) which improves the surface roughness and increases the surface tendency for reaction with hydrogen.

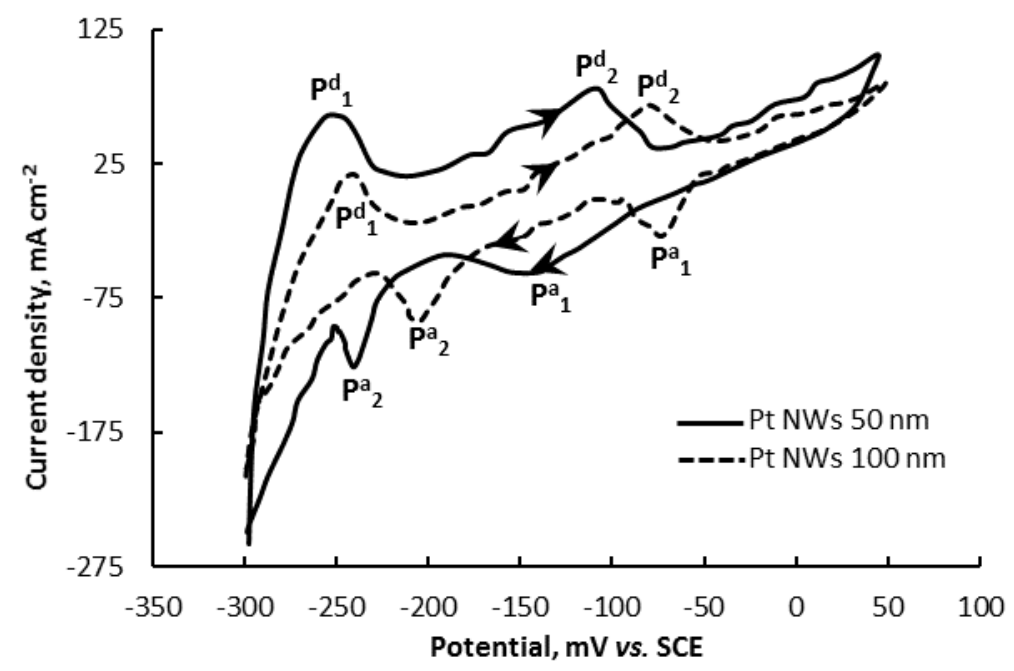

Figure 9. Cyclic voltammograms of Pt NWs 50 and $100 \mathrm{~nm}$ in $0.5 \mathrm{M} \mathrm{H}_{2} \mathrm{SO}_{4}$ solution at scan rate of $50 \mathrm{mV} \mathrm{s}^{-1}$

\section{Methanol oxidation}

The CV curves presented in Figure 10 display the methanol oxidation performance of Pt NWs deposited at the potential of $-400 \mathrm{mV}$ for $3000 \mathrm{~s}$ on PCT $50 \mathrm{~nm}$ and for $850 \mathrm{~s}$ on PCT $100 \mathrm{~nm}$, in a 
$0.5 \mathrm{M} \mathrm{H}_{2} \mathrm{SO}_{4}+2 \mathrm{M} \mathrm{CH}_{3} \mathrm{OH}$ solution. It can be observed that in the anodic scans, the methanol oxidation reactions begin at 230 and $473 \mathrm{mV}$ for Pt NWs 50 and $100 \mathrm{~nm}$, respectively. The onset oxidation potential for Pt NWs $50 \mathrm{~nm}$ is less positive compared to that of Pt NWs $100 \mathrm{~nm}$, indicating that the morphology of Pt NWs $50 \mathrm{~nm}$ reduces the required initial potential and promotes the methanol oxidation. With the increase of the potential in the anodic sweep, the methanol molecules are dissociatively chemisorbed on Pt nanowires. As the potential is swept toward more anodic values, the anodic $P_{1}$ peaks emerge at 920 and $1032 \mathrm{mV}$ for Pt NWs 50 and $100 \mathrm{~nm}$, respectively. These peaks are attributed to the production of intermediates, poisonous $\mathrm{Pt}=\mathrm{C}=\mathrm{O}$ species, and carbon dioxide on the surface of the electrode. The lower value of the potential at $P_{1}$ peak for Pt NWs $50 \mathrm{~nm}$ in comparison to Pt NWs $100 \mathrm{~nm}$ is indicative of the reduced required potential for methanol oxidation on smaller nanowires. Moreover, the current value at $P_{1}$ peak for Pt NWs $50 \mathrm{~nm}$ is higher than that of Pt NWs $100 \mathrm{~nm}$, which can be justified by the unique pine-tree morphology of nanowires and their larger ratio of surface-to-volume, leading to the higher accessibility of these nanowires for trapping the guest molecules. Thus, the adsorption of intermediate species on the surface of the Pt NWs $50 \mathrm{~nm}$ is enhanced and the methanol oxidation is intensified.

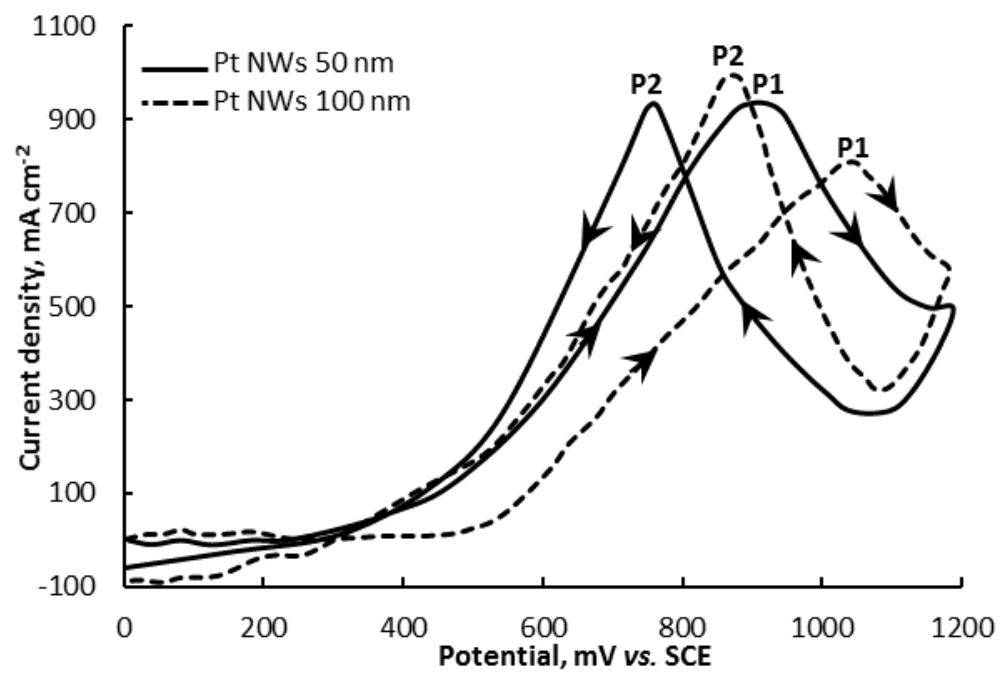

Figure 10. Cyclic voltammetry curves for methanol oxidation on Pt NWs 50 and $100 \mathrm{~nm}$ in a solution containing $0.5 \mathrm{M} \mathrm{H}_{2} \mathrm{SO}_{4}$ and $2 \mathrm{M} \mathrm{CH}_{3} \mathrm{OH}$ at scan rate of $50 \mathrm{mV} \mathrm{s}^{-1}$

In the backward scan, the cathodic $P_{2}$ peaks can be observed at 756 and $867 \mathrm{mV}$ for Pt NWs 50 and $100 \mathrm{~nm}$, respectively, due to the removal of poisonous $\mathrm{Pt}=\mathrm{C}=\mathrm{O}$ species. It is obvious that the $\mathrm{P}_{2}$ peak appears at a more positive potential and with a higher current value for Pt NWs $100 \mathrm{~nm}$ compared to $\mathrm{Pt}$ NWs $50 \mathrm{~nm}$. This is due to the higher amount of $\mathrm{Pt}=\mathrm{C}=\mathrm{O}$ species produced on $\mathrm{Pt}$ NWs $100 \mathrm{~nm}$ during the forward scan. Therefore, their oxidation is more difficult and requires higher potential and current values. Although Pt NWs act as effective catalysts for methanol oxidation, they tend to be poisoned by carbon monoxide [25]. The higher ratio of currents at $P_{1}$ peak to $\mathrm{P}_{2}$ peak represents the improved tolerance of nanowires toward the poisoning by carbon monoxide [26]. Regarding Figure 10, this ratio is estimated to be 1.02 and 0.78 for Pt NWs 50 and $100 \mathrm{~nm}$, respectively, demonstrating that the Pt NWs $50 \mathrm{~nm}$ possess an enhanced poisoning tolerance. This feature, in addition to the reduced onset and $P_{1}$ peak potentials leads to the enhanced electrocatalytic activity of these nanowires. The superior electrocatalytic performance of the nanowires prepared on PCT $50 \mathrm{~nm}$ is attributed to the higher value of surface-to-volume ratio of these nanowires, providing more uncovered active sites for trapping methanol molecules 
for their subsequent oxidation. Furthermore, the pine-tree morphology of Pt NWs $50 \mathrm{~nm}$ provides enhanced electrocatalytic efficiency in comparison to the spherical morphology of Pt NWs $100 \mathrm{~nm}$.

\section{Conclusion}

The platinum nanowires with different diameters were fabricated by the template-assisted electrodeposition technique. The deposition process was characterized by the voltammetry method and it was confirmed that addition of sulfuric acid to the plating bath accelerates deposition of Pt NWs. The influence of different potential scan rates on the electrodeposition of Pt NWs was investigated. It was observed that at low scan rates, two cathodic peaks appeared in the cyclic voltammetric curves, implying that the diffusion-controlled reduction of platinum ions occurred through two successive steps. However, at high scan rates, the presence of one cathodic peak on the voltammograms proved the incomplete and direct reduction of ions. The linear voltammetric curves obtained for different templates revealed that while the deposition was under charge transfer control on PCT $15 \mathrm{~nm}$, the diffusion-controlled deposition occurred on PCT 50 and $100 \mathrm{~nm}$. Morphological studies of NWs synthesized by the potentiostatic deposition technique revealed that at short deposition durations and under less negative deposition potentials, the growth of nanowires occurred simultaneously and uniformly. Less uniform growth of nanowires took place under more negative potentials due to the hydrogen evolution reaction. Moreover, at longer deposition durations, the platinum nanowires on PCT 50 and $100 \mathrm{~nm}$ possessed pine-tree and spherical structures, respectively. Based on the CV curves obtained in acidic solutions for deposits with an identical exchanged charge, the nanowires grown on PCT 50 $\mathrm{nm}$ exhibited enhanced catalytic performance toward hydrogen adsorption/desorption and methanol oxidation reactions compared to nanowires deposited on PCT $100 \mathrm{~nm}$. This was ascribed to the higher surface-to-volume ratio, larger electrochemical active surface area, and the higher density of exposed active sites available on the pine-tree structure of Pt NWs $50 \mathrm{~nm}$.

\section{References}

[1] K. I. Ozoemena, Royal Society of Chemistry 6 (2016) 89523-89550.

[2] E. P. Lee, Y. Xia, Nano Research 1 (2008) 129-137.

[3] G. R. O. Almeida, E. M. Sussuchi, C. T. D. Meneses, G. R. Salazar-Banda, K. I. B. Eguiluz, International Journal of Electrochemical Science 12 (2017) 7502-7517.

[4] W. Liu, J. Huang, Journal of Power Sources 189 (2009) 1012-1015.

[5] K. Tao, J. Wang, Y. Li, D. Xia, H. Shan, H. Xu, J. R. Lu, Scientific Reports 3 (2013) 1-6.

[6] Y. Lu, S. Du, R. Steinberger-Wilckens, Applied Catalysis B: Environmental 164 (2015) 389-395.

[7] S. Sun, G. Zhang, D. Geng, Y. Chen, R. Li, M. Cai, X. Sun, Angewandte Chemie International Edition 50 (2011) 422-426.

[8] L. Rotkina, Applied Physics Letters 83 (2003) 4426-4428.

[9] B. Y. Xia, H. B. Wu, Y. Yan, X. W. Lou, X. Wang, Journal of the American Chemical Society 135 (2013) 9480-9485.

[10] L. A. Dobrzanski, M. Szindler, M. Pawlyta, M. M. Szindler, P. Boryło, B. Tomiczek, Open Physics 14 (2016) 159-165.

[11] A. M. Contreras, J. Grunes, X. M. Yan, A. Liddle, G. A. Somorjai, Catalysis Letters 100 (2005) 115-124.

[12] P. Brault, A. Caillard, S. Baranton, M. Mougenot, S. Cuynet, C. Coutanceau, ChemSusChem 6 (2013) 1168-1171.

[13] S. S. Mahshid, A. Dolati, S. Hashemi Daryan, M. Ghorbani, ECS Transactions 28 (2010) 25-35.

[14] G. Nabiyouni, K. Hedayati, Journal of Experimental Nanoscience 9 (2014) 186-196.

[15] X. Z. Gong, J. N. Tang, J. Q. Li, Y. K. Liang, Transactions of Nonferrous Metals Society of China 18 (2008) 642-647.

[16] W. B. Yu, G. Ouyang, Scientific Reports 7 (2017) 1-7. 
[17] J. M. Nugent, K. S. V. Santhanam, A. Rubio, P. M. Ajayan, Nano Letters 1 (2001) 87-91.

[18] E. Broaddus, J. Brubaker, S. A. Gold, International Journal of Electrochemistry 2013 (2013) 1-7.

[19] S. Mohajeri, A. Dolati, M. Ghorbani, Journal of Ultrafine Grained and Nanostructured Materials 49 (2016) 51-63.

[20] J. Chen, B. Lim, E. P. Lee, Y. Xia, Nano Today 4 (2009) 81-95.

[21] Y. J. Song, S. B. Han, K. W. Park, Materials Letters 64 (2010) 1981-1984.

[22] E. S. V. Neto, M. A. Gomes, G. R. Salazar-Banda, K. I. B. Eguiluz, International Journal of Hydrogen Energy 43 (2018) 178-188.

[23] S. Sun, G. Zhang, D. Geng, Y. Chen, M. N. Banis, R. Li, M. Cai, X. Sun, Chemistry-A European Journal 16 (2009) 829-835.

[24] H. A. Gasteiger, S. S. Kocha, B. Sompalli, F. T. Wagner, Applied Catalysis B: Environmental 56 (2005) 935.

[25] S. M. Alia, S. Pylypenko, K. C. Neyerlin, S. S. Kocha, B. S. Pivovar, Journal of The Electrochemical Society 162 (2015) 1299-1304.

[26] C. Xu, L. Wang, R. Wang, K. Wang, Y. Zhang, F. Tian, Y. Ding, Advanced Materials 21 (2009) 2165-2169.

(C2018 by the authors; licensee IAPC, Zagreb, Croatia. This article is an open-access article distributed under the terms and conditions of the Creative Commons Attribution license (http://creativecommons.org/licenses/by/4.0/) 